\title{
Long-Term Peritoneal Dialysis Treatment Provokes Activation of Genes Related to Adaptive Immunity
}

\author{
A. PARIKOVA ${ }^{1}$, P. HRUBA ${ }^{2}$, R. T. KREDIET ${ }^{3}$, Z. KREJCIK ${ }^{4}$, V. STRANECKY ${ }^{5}$, \\ I. STRIZ ${ }^{6}$, O. VIKLICKY ${ }^{1}$
}

${ }^{1}$ Department of Nephrology, Institute for Clinical and Experimental Medicine, Prague, Czech Republic, ${ }^{2}$ Transplant Laboratory, Institute for Clinical and Experimental Medicine, Prague, Czech Republic, ${ }^{3}$ Department of Nephrology, Amsterdam UMC University of Amsterdam, Netherlands, ${ }^{4}$ Institute of Haematology and Blood Transfusion, Prague, Czech Republic, ${ }^{5}$ Institute of Inherited Metabolic Disorders, Prague, Czech Republic, ${ }^{6}$ Department of Clinical and Transplant Immunology, Institute for Clinical and Experimental Medicine, Prague, Czech Republic

Received March 1, 2019

Accepted June 10, 2019

Epub Ahead of Print August 19, 2019

\begin{abstract}
Summary
Permanent irritation of the peritoneum during peritoneal dialysis (PD) treatment leads to local chronic inflammation and subsequently activation of processes driving fibrogenesis in the long-term. The aim of the study was to compare the peritoneal effluent transcriptome of 20 patients treated less and 13 patients treated more than 2 years using microarray analysis. An increased expression of genes associated with an immune response was observed in long-term treated patients with well preserved peritoneal function, when compared to patients treated less than 2 years. From 100 genes highly expressed in long-term patients, a significant up-regulation of six was found by RT-qPCR: LY9 (lymphocyte antigen 9), TNSFR4 (tumor necrosis factor receptor superfamily, member 4), CD 79A (CD79a molecule), CCR7 (chemokine C-C receptor 7), CEACAM1 (carcinoembryonic antigen-related cell adhesion molecule 1) and IL2RA (interleukin 2 receptor alpha chain). Furthermore, the effluent cell population was analysed. A positive relationship between the number of granulocytes and NK cells on one hand, and duration of PD treatment on the other, was shown. We conclude, that the mechanisms of adaptive immunity promoting Thelper 2 cells response are activated in the long-term before functional alterations develop. It consequently might trigger the fibrosis promoting processes.
\end{abstract}

\section{Key words}

Peritoneal dialysis • Gene expression • Peritoneal membrane alterations

\section{Corresponding author}

A. Parikova, Department of Nephrology, Institute for Clinical and Experimental Medicine, Videnska 1958/4, 14021 Prague 4, Czech Republic. E-mail: alpk@medicon.cz

\section{Introduction}

Peritoneal dialysis treatment is accompanied with alterations of the peritoneal membrane. Chronic inflammation resulting in angiogenesis and fibrogenesis has been suggested to be the key moment in the development of peritoneal membrane changes (Davies 2014). Fibrogenesis is a complex process, primarily mediated by activated myofibroblasts producing collagen. Different regulators of individual importance are entangled. Of immune cells, mainly macrophages, but also $\mathrm{T}$ cells are involved in the pro-fibrotic response through cytokines release (Aufricht et al. 2017). Interleukin 6 (IL-6) is secreted by $\mathrm{T}$ cells and macrophages within an immune response to specific microbial stimuli to resolve infection and local tissue damage. This cytokine plays a pivotal role in the switch from innate immune response to an adaptive immune 
reaction (Aufricht et al. 2017). In experimental model of sustained innate inflammatory activation, IL-6 subsequently triggers Th1 cell-mediated altered immune response, thereby promoting fibrosis via regulation of matrix metalloproteinases (Fielding et al. 2014). Activated Th2 lymphocytes show a pro-fibrotic potential through cytokine release, which stimulates collagen production and fibroblast to myofibroblast differentiation (Pesce et al. 2006). B cells might also be involved in fibrosis by regulation of T cell activation and IL6 release as a consequence of their antigen-presenting and co-stimulatory capacity (Hasegawa et al. 2005). Development of fibrosis is accompanied by neoangiogenesis due to release of various pro-angiogenic chemokines and growth factors also involved in fibrotic processes (Wynn 2008).

The balance between ongoing chronic inflammation, tissue remodelling and tissue repair affects the development of peritoneal membrane alterations and might be different depending on the duration of PD treatment. The aim of the present study was to elucidate genes potentially involved in peritoneal alterations during $\mathrm{PD}$ treatment by comparing the transcriptome of peritoneal cells in short- and long-term PD patients.

\section{Patients and methods}

The long-dwell PD effluents (median duration of $9 \mathrm{~h}$, range 8-14) of the dwell performed with a glucose based dialysis solution were acquired from 33 stable patients (21 males, 12 females) and centrifuged to obtain peritoneal cells for gene expression profiling using microarray analysis and for flow cytometry analysis. A 4-hour $3.86 \%$ glucose peritoneal equilibration test (PET) was performed on the day after the long-dwell collection in all patients. The patients showed no signs of infection at the time of examination and were peritonitis free at least 4 weeks preceding the test. Afterward, microarray results were validated in a larger cohort of 57 patients (validation set). The study protocol was approved by the Ethics Committee of the Institute for Clinical and Experimental Medicine.

Eight patients were treated with automated peritoneal dialysis (APD), the others with continuous ambulatory peritoneal dialysis (CAPD). All of them used commercially available glucose based dialysis solutions (Dianeal ${ }^{\circledR}$, Baxter Healthcare Ltd., IRL-Dublin, Ireland). All but three used $7.5 \%$ icodextrin (Extraneal ${ }^{\circledR}$, Baxter
Healthcare Ltd., IRL-Dublin, Ireland) for the long dwell.

The patients were divided into a short-term PD group with a duration of PD treatment between 0 and 24 months and into a long-term one with a PD duration $\geq 25$ months.

\section{Peritoneal equilibration test (PET)}

The PETs were performed during a four hours dwell with a $3.86 \%$ glucose dialysis solution (Dianeal ${ }^{\circledR}$ ) under standardized conditions as described previously (Smit et al. 2003). The test itself was preceded in all patients by a rinsing procedure with fresh $1.36 \%$ glucose dialysis solution to avoid a possible effect of residual peritoneal volume before the test, on calculations of transport parameters. During the PET temporary drainage after $1 \mathrm{~h}$ for assessment of free water transport was performed (Cnossen et al. 2009). Blood samples were collected at 60, 120, $240 \mathrm{~min}$. The dialysate samples were taken at multiple time points after inflow of the test solution: $0,60,120$ and $240 \mathrm{~min}$ ).

The dialysate over plasma ratio of creatinine $\left(\mathrm{D} / \mathrm{P}_{\text {creat }}\right)$ and ratio of glucose concentration at $240 \mathrm{~min}$ over that at start of the dwell $\left(\mathrm{D} / \mathrm{D}_{0}\right)$ glucose were assessed. Net ultrafiltration (NUF) is the difference between the in-situ intraperitoneal volume and the initial one. The fluid transport through the small pores $\left(\mathrm{SPFT}_{60}\right)$ was computed by dividing the amount of transported sodium within first hour with the plasma sodium concentration. The fluid transport through the small pores was then subtracted from the net ultrafiltered fluid volume after one hour, resulting in free water transport within first $60 \mathrm{~min}\left(\mathrm{FWT}_{60}\right)$.

\section{Gene expression profiling}

Gene expression profiling of peritoneal cells was analysed using microarray on Illumina Human HT-12 v4 Expression BeadChips.

Peritoneal cells were obtained from peritoneal effluent of the long dwell preceding the PET by five consecutive centrifugations of $50 \mathrm{ml}$ at $5000 \mathrm{~g}, 5^{\circ} \mathrm{C}$ for $20 \mathrm{~min}$ and stored at $-20^{\circ} \mathrm{C}$ in lysis buffer until RNA isolation. Total RNA was isolated from using the RNeasy Micro Kit (Qiagen, Hilden, Germany) according to the manufacturer's instructions.

Only RNA samples with an RNA integrity number $>6.5$, as measured using the Agilent RNA 6000 Nano Kit on the Agilent 2100 Bioanalyzer (Agilent Technologies) were used for microarray analysis. A total of $200 \mathrm{ng}$ of purified RNA served as a template for the 
amplification and biotinylation of cRNA using the Illumina ${ }^{\circledR}$ TotalPrep ${ }^{\mathrm{TM}}$ RNA Amplification Kit, according to the manufacturer's instructions. Yields of labeled cRNA were determined using the Agilent RNA 6000 Nano Kit on the Agilent 2100 Bioanalyzer (Agilent Technologies). Labeled cRNA (950 ng) was hybridized at $58{ }^{\circ} \mathrm{C}$ for $16 \mathrm{~h}$ to Illumina HumanHT-12 v4.0 Expression BeadChips (Illumina, Inc., San Diego, CA), and then washed according to the manufacturer's instructions. After hybridization, the chip was scanned using the BeadStation 500 instrument (Illumina), and raw data were extracted with the BeadStudio Data Analysis Software (Illumina). The R software lumi package was used to process the raw data. The quantile method was used for normalization.

\section{Flow cytometry analysis}

Leukocyte subtypes within peritoneal cells where phenotyped by a NAVIOS flow cytometer (Beckman Coulter, Brea, CA, USA). The expression of the surface markers CD45, CD3, CD4, CD8, CD19, CD16, CD56 and, CD14 was examined using DuraClone IM Phenotyping Basic tubes with dried antibody panels (Beckman Coulter, Brea, CA) and the data were processed by Kaluza software (Beckman Coulter, Brea, CA). B cells were identified as $\mathrm{CD} 45^{+} \mathrm{CD} 19^{+}$; $\mathrm{T}$ cells as $\mathrm{CD} 45^{+} \mathrm{CD}^{+}$; $\mathrm{CD} 8$ cytotoxic $\mathrm{T}$ cells as $\mathrm{CD} 45^{+} \mathrm{CD} 3^{+} \mathrm{CD} 8^{+}$; CD4 $\mathrm{T}$ helper cells as $\mathrm{CD} 45^{+} \mathrm{CD} 3{ }^{+} \mathrm{CD} 4{ }^{+}$; natural killer (NK) cells as $\mathrm{CD} 45^{+} \mathrm{CD} 3^{-} \mathrm{CD} 56^{+}$; monocytes as $\mathrm{CD} 45^{+} \mathrm{CD} 14^{+}$and granulocytes as $\mathrm{CD} 45^{+}$versus side scatter integral.

\section{Measurements}

Plasma and effluent concentrations of urea and creatinine were measured by enzymatic methods on an automated analyzer (Abbott Architect analyzer: Abbott Laboratories, Abbott Park, IL, USA). Sodium concentrations were determined using the indirect ion selective electrode method. Glucose was measured on an autoanalyzer (Abbott Architect analyzer: Abbott Laboratories, Abbott Park, IL, USA) by the enzymatic hexokinase assay.

\section{Statistical analysis}

Data are presented as medians and ranges, unless stated otherwise. The Mann-Whitney U test was used to compare the transport parameters and AR of the shortand long-term PD patients due to asymmetrically distributed data. Spearman's rank correlation coefficient was used to examine possible relationships. All statistical analyses were performed using GraphPad Prism5.

Regarding gene analysis, only probes with average expression $>3.5$ were used for further analysis. Differentially expressed genes were chosen as those with fold change $>2$ and an adjusted $\mathrm{p}$ value for multiple testing $<0.05$. The affected genes were functionally annotated, and the deregulated pathways were identified with the David database (http://david.abcc.ncifcrf.gov). The complete raw and normalized data have been deposited in the NCBI Gene Expression Omnibus (GEO) database and are accessible through the GEO Series accession number GSE125498 (https://www.ncbi.nlm.nih.gov/geo/query/acc.cgi?acc $=\mathrm{G}$ SE125498). Venn's diagrams were constructed using an interactive tool for comparing lists of genes (http://bioinfogp.cnb.csic.es/tools/venny/index.html).

\section{Results}

Patient characteristics and their peritoneal transport parameters are presented in Table 1. As expected the long-term treated patients had lower values of residual urine volume $(\mathrm{p}<0.01)$. Furthermore, longterm patients suffered more peritonitis episodes than short-term ones. No relationship between peritonitis incidence and net ultrafiltration was observed $(\mathrm{r}=-0.3$, $\mathrm{p}=0.1$ ). However, plasma CRP and peritoneal functional tests were not different between the groups. A normal peritoneal function was defined as the presence of both $\mathrm{D} / \mathrm{P}$ creatinine $<0.8$ and netUF $>400 \mathrm{ml}$ at the end of the PET.

Using microarray, gene annotation analysis of up-regulated genes in the long-term PD group showed significant enrichment of 8 genes in GO term related to cell activation (CXCR5, CD79A, CD24, TNFRSF4, LTB, HSH2D, FLT3LG, RHOH), 7 genes in GO term related to lymphocyte activation (CXCR5, CD79A, CD24, TNFRSF4, HSH2D, FLT3LG, RHOH), 7 genes related to leukocyte activation (CXCR5, CD79A, CD24, TNFRSF4, HSH2D, FLT3LG, RHOH), 10 genes associated with immune response (CCR7, POU2AF1, IL2RA, CST7, LY9, CD79A, CD24, TNFRSF4, LTB, HLA-DOB), 5 genes related to cytokine binding (CCR7, IL2RA, CXCR5, TNFRSF25, TNFRSF4) and 7 genes involved in the cytokine-cytokine receptor interaction pathway (CCR7, IL2RA, CXCR5, TNFRSF25, TNFRSF4, LTB, FLT3LG).

To further investigate the influence of duration 
of PD treatment on gene activity, patients in the longterm group were divided according to peritoneal transport parameters, $\mathrm{D} / \mathrm{P}_{\text {creat }}<$ and $\geq 0.8$ and net ultrafiltration $\leq$ and $>400 \mathrm{ml}$. Venn diagrams were constructed with the aim to exclude an effect of PD- associated functional alterations (Fig. 1). From 100 overlapping genes distinguishing short-and long-term patients ( $\mathrm{PD} \leq 2$ years vs. PD $>2$ years) and concurrently patients with normal peritoneal function and an impaired PET (D/ $\mathrm{P}_{\text {creat }}<0.8$ vs. $\mathrm{D} / \mathrm{P}_{\text {creat }} \geq 0.8$ and netUF $>400 \mathrm{ml}$ vs. netUF $\leq 400 \mathrm{ml}$ ), only 22 were influenced by peritoneal function and the remaining 78 by the duration of PD treatment. Genes affected largely by peritoneal function were associated with plasma membrane signals, while the genes impacted by PD duration were associated with immune system activation and immune response. 36 transcripts from these above mentioned 78 overlapping genes, were simultaneously increased significantly in long-term patients compared to short-term PD in the original microarray analysis (Table S1). Eleven genes with the most significant difference between short- and long-term PD (CD79A, CXCR5, CCR7, CEACAM1, LTB, POU2AF1, TNFRSF25, LY9, FLT3LG, IL2RA, RHOH) were selected for validation by RT-qPCR in a larger validation cohort of 57 patients. Finally, a higher expression validated by RT-qPCR was found in LY9 (lymphocyte antigen 9) $(p=0.004)$, CD79A (CD79a molecule, immunoglobulin-associated alpha) $(\mathrm{p}=0.032)$, CEACAM1 (carcinoembryonic antigen-related cell adhesion molecule 1) $(\mathrm{p}=0.032), \mathrm{CCR} 7 \quad$ (chemokine (C-C motif) receptor 7) $(\mathrm{p}=0.037)$, and IL2RA (interleukin 2 receptor, alpha chain) $(\mathrm{p}=0.041)$.

Table 1. Clinical and functional characteristic of the patients.

\begin{tabular}{|c|c|c|}
\hline & Short-term PD $(n=20)$ & Long-term PD $(n=13)$ \\
\hline Gender (\%male) & 60 & 70 \\
\hline Age at PET (years) & $46(29-69)$ & $61(33-74)^{\mathbf{a}}$ \\
\hline \multicolumn{3}{|l|}{ Primary kidney disease (\%) } \\
\hline Diabetic nephropathy & 10 & 31 \\
\hline Renovascular nephropathy & 10 & 7 \\
\hline Glomerulonephritis & 35 & 41 \\
\hline Interstitial nephritis & 10 & 7 \\
\hline Polycystic kidney disease & 25 & 7 \\
\hline Others and unknown & 10 & 7 \\
\hline PD duration (months) & $5(2-24)$ & $43(25-68)$ \\
\hline$C R P(m g / l)$ & $3.3(0.7-13.2)$ & $2.2(0.2-6.3)$ \\
\hline $\begin{array}{l}\text { Renal creatinine clearance at the time of the } \\
P E T\left(\mathrm{ml} / \mathrm{min} / 1.73 \mathrm{~m}^{2}\right)\end{array}$ & $5.1(0-11.7)$ & $1.0(0-9.0)$ \\
\hline Residual diuresis $(\mathrm{ml} / 24 \mathrm{~h})$ & $1500(0-2,500)$ & $250(0-1,750)^{\mathbf{b}}$ \\
\hline Anuric patients at the time of PET (\%) & 15 & $61^{\mathrm{b}}$ \\
\hline Peritoneal KT/V urea (per week) & $1.5(0.6-2.3)$ & $1.5(0.6-2.1)$ \\
\hline Net $U F$ at $240 \min (\mathrm{ml})$ & $300(-400-810)$ & $470(-500-950)$ \\
\hline SPT at $60 \mathrm{~min}(\mathrm{ml})$ & $175(62-380)$ & $177(36-556)$ \\
\hline FWT at $60 \mathrm{~min}(\mathrm{ml})$ & $118(68-300)$ & $144(16-314)$ \\
\hline$D / P_{\text {creatinine }}$ & $0.8(0.6-0.9)$ & $0.8(0.6-0.9)$ \\
\hline $\mathrm{D} / \mathrm{P}_{\text {sodium }}$ at $60 \mathrm{~min}$ & $0.9(0.8-1.1)$ & $0.9(0.8-1.0)$ \\
\hline UF failure patients (\%) & 60 & 46 \\
\hline Patients without peritonitis episode (\%) & 50 & $23^{\mathrm{b}}$ \\
\hline Patients with 1/2/3 peritonitis episodes (\%) & $35 / 10 / 5$ & $23 / 23 / 31^{\text {a }}$ \\
\hline
\end{tabular}

PD: peritoneal dialysis; PET: peritoneal equilibration test; CRP: C reactive protein; UF: ultrafiltration; SPT: small pore fluid transport; FWT: free water transport. UF failure was defined as net ultrafiltration of less than $400 \mathrm{ml}$ after a $4 \mathrm{~h}$ dwell with $3.86 \%$ glucose. Values are expressed as median and ranges. ${ }^{a} \mathrm{p}<0.05$ short-term vs. long-term; ${ }^{b} \mathrm{p}<0.01$ short-term vs. long-term. 
A

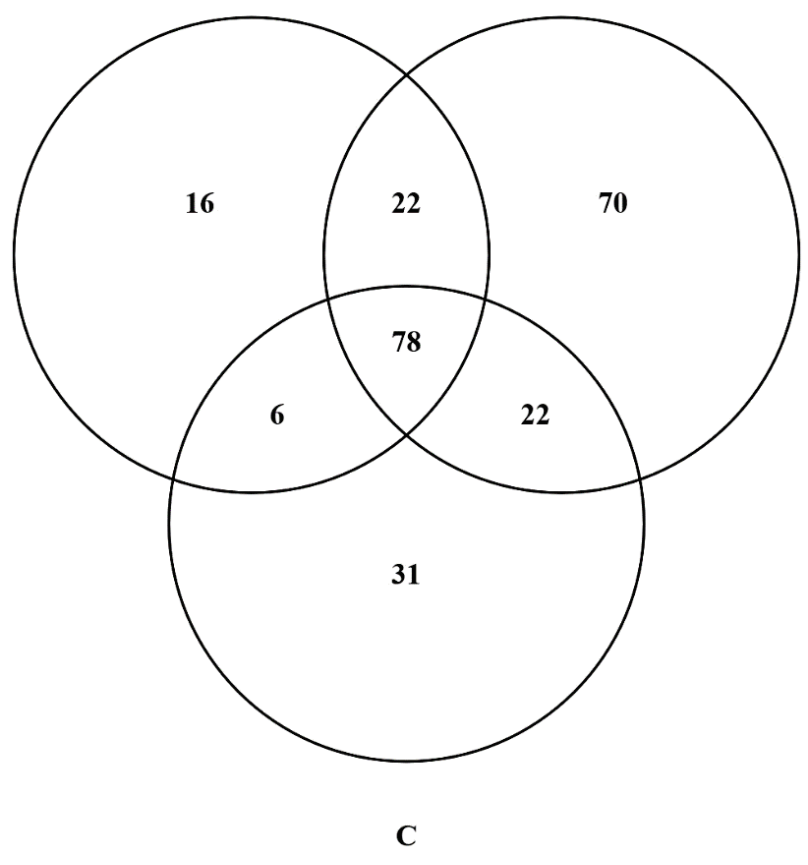

Fig. 1. Venn diagram showing the number of overlapping upregulated genes in long-PD patients with better functional test compared to short-PD patients with worse functional test. A segment: long-term treated patients with $D / P_{\text {creat }}<0.8$ compared to short-term patients with $D / P_{\text {creat }}>0.8$; B segment: long-term treated patients with NUF (net ultrafiltration) $>400 \mathrm{ml}$ compared to short-term patients with NUF $\leq 400 \mathrm{ml}$; C segment: short-term treated patients compared to long-term patients without regard to functional test results. The number in each circle (segment) represents the differentially expressed genes between the compared groups. The overlapping number stands for the mutual differentially expressed genes between the different comparisons (segments). The non-overlapping numbers represent the genes unique to each condition.

To rule out the influence of cell composition of peritoneal effluent on gene activation, the proportional representation of effluent cell components was investigated. No difference in absolute counts was found between short- and long-term treated groups. No relationships between PD duration and total leukocyte count $(\mathrm{r}=-0.2 ; \mathrm{p}=0.3)$, nor between duration of $\mathrm{PD}$ and absolute counts of macrophages $(\mathrm{r}=-0.2 ; \mathrm{p}=0.4)$, and polymorphonuclears $(r=-0.1, p=0.4)$ were observed. The peritoneal $\mathrm{CD} 45^{+}$cell population consisted primarily of monocytes (37\%). Lymphocytes comprised $22 \%$, granulocytes $19 \%$ and NK cells $15 \%$. T cells accounted for $55 \%$ and B cells for $12 \%$ of the lymphocyte population. A positive relationship was present between PD duration and the proportion of granulocytes $(\mathrm{p}=0.02)$ and NK cells ( $\mathrm{p}=0.01$ ), but not for B cells (Fig. 2).

\section{Discussion}

In the present study the transcriptome profile in peritoneal effluent of short- and long-term PD patients was analysed. T cell related transcripts and genes associated with cytokine activation showed increased expression in long-term PD patients. Furthermore, the number of granulocytes and NK cells increased with the time on PD treatment.

Chronic exposure to dialysis solutions during peritoneal dialysis treatment leads to persistent microinflammation of the peritoneum and subsequently activation of processes driving fibrogenesis in the longterm. Continuous exposure to bio-incompatible dialysis fluids provokes influx of inflammatory cells towards the peritoneal cavity. Alike other studies, also in the present study monocytes and lymphocytes were the most prevalent cell population in peritoneal effluent (Rodrigues-Diez et al. 2014, Betjes et al. 2015). The majority of lymphocytes in the present study consisted of $\mathrm{T}$ cells. Immune status in general results from the balance between type 1 (Th1), type 2 (Th2), and type 17 (Th17) helper T cell subsets activity. In PD patients, influx of $\mathrm{T}$ cells mounting a Th1-polarized response with a pro-inflammatory cytokine profile has been observed (Betjes et al. 2015). The increase in the number of granulocytes and NK cells with duration of PD might reflect persistent bacterial load and infectious complications associated with PD treatment.

In our study higher expressions of $L Y 9$ (lymphocyte antigen 9, TNFRSF4 (tumor necrosis factor receptor superfamily member 4 ) and $I L 2 R A$ (interleukin 2 receptor alpha chain) were observed in the long-term group. LY9 belongs to signalling lymphocyte activation molecule (SLAM) family receptor involved in innate and adaptive immune responses (Graham et al. 2006). Assistance of $L Y 9$ in Th2 and Th17 polarization leading to increased IL-17 secretion has been described (Graham et al. 2006, Chatterjee et al. 2012). Intraperitoneal application of IL-17 induces an increase in expression of proinflammatory and profibrotic factors (Rodriques et al. 2014). Enhanced expression of $L Y 9$ reflecting immune activation within the peritoneal cavity might contribute to elevated IL-17 effluent concentrations found in long-term PD patients (Rodriques et al. 2014). TNFRSF4, a member of TNFR superfamily, is a costimulatory molecule for $\mathrm{T}$ cell proliferation. It is expressed on activated and regulatory $\mathrm{T}$ (Treg) cells (Klinger et al. 2009). Activation of TNSFR4 by binding of his ligand 
A

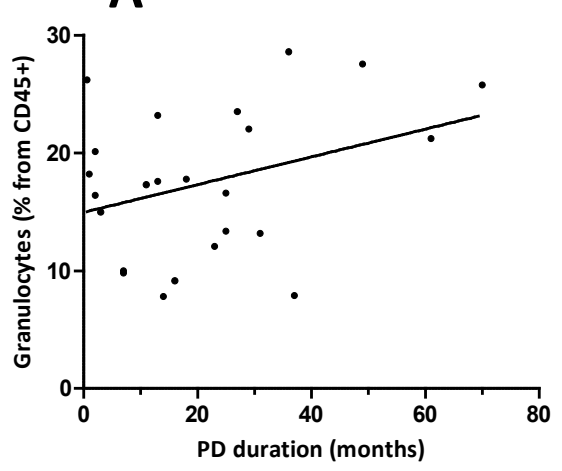

B

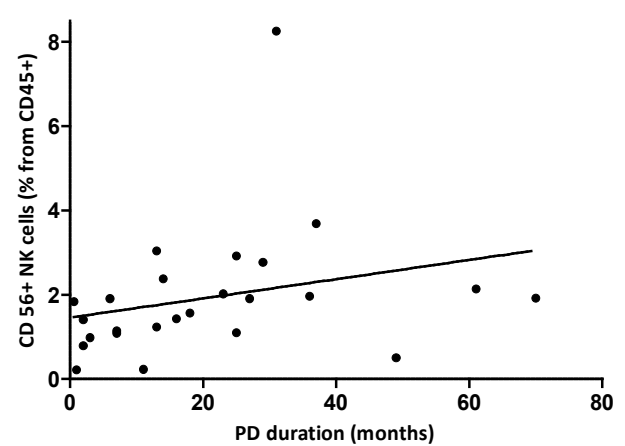

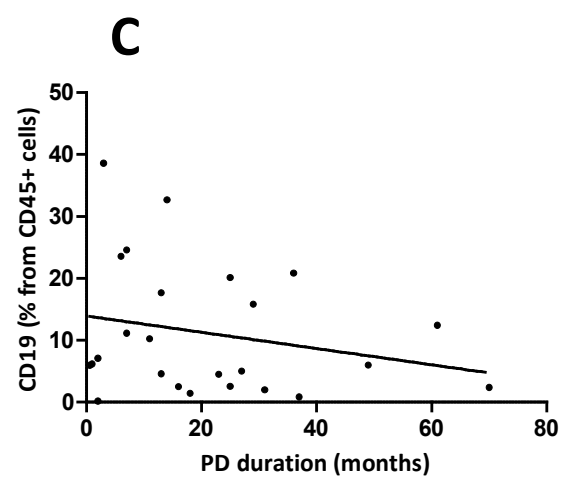

Fig. 2. A positive correlation was present between $P D$ duration and (A) percentage of granulocytes $(r=0.47, p=0.02)$, and $(\mathbf{B})$ percentage of NK cells $(r=0.50, p=0.01)$. (C) The proportion of B lymphocytes (CD19 positive cells) was not related to PD duration $(r=-0.22, p=0.30)$.

launches cytokine production and promotes the differentiation of naive $\mathrm{CD}^{+} \mathrm{T}$ cells into $\mathrm{Th} 2$ cells (Ohshima et al. 1998). The IL2RA gene encodes interleukin-2 receptor alpha chain (IL-2RA, also named CD25), a component of interleukin receptor 2 (IL-2R). IL-2RA is expressed upon antigen activation mainly on resting $\mathrm{T}$ regulatory or activated $\mathrm{T}$ cells (Triplett et al. 2012) to bind interleukin 2 (IL2). IL2 is a pleiotropic cytokine, which modulates expression of other cytokine receptors, contributes to differentiation of naïve $\mathrm{CD}^{+} \mathrm{T}$ cells into regulatory $\mathrm{T}$ cells, is involved in activation-induced cell death, in modulating $\mathrm{T}$ helper cell differentiation and plays an important role in the early phase of Th2 cells differentiation (Liao et al. 2011).

The adaptive branch of the immune system is contingent on $\mathrm{B}$ and $\mathrm{T}$ cell activations in response to antigenic stimulation to the elimination of antigen and ensuring of lasting protection from invasion with the same pathogen. B cell activation starts with B cell antigen receptor stimulation either by antigen or by a tonic survival signal in the absence of antigen stimulation (Yasuda et al. 2017). The CD79A gene encodes immunoglobulin-associated alpha, a part of B cell antigen receptor (BCR) (Allam et al. 2004). As a higher peritonitis incidence was found the long-term group, the higher expression of $C D 79 \mathrm{~A}$ in this patient group might reflect a prolonged pathogenic environment throughout the peritoneal cavity in the long-term PD patients, which launches the protective mechanisms enhancing an adaptive response to antigenic stimulation by $\mathrm{B}$ cell activation.

High glucose content and advanced glycosylation end products (AGEs) in dialysis solutions have been repeatedly shown to induce macrophage activation (Ohashi et al. 2010). The M2 phenotype macrophages induced by $\mathrm{T}$ helper 2 cells under influence of cytokines, are involved in tissue remodeling and fibrosis via TGF beta/Smad signaling pathways (Hu et al. 2012). The upregulation of CCR7 follows classical activation of M1 phenotype macrophages by lipopolysaccharide and interferon- $\gamma$ (INF $\gamma)$. Activated macrophages start to produce pro-inflammatory cytokines, like INF $\gamma$ and tumor necrosis factor (TNF $\alpha$ ). These are predominantly involved in inflammation, tissue damage and killing of intracellular microbes (Mosser and Edwards 2008). On the other hand, the CCR7 receptor and its ligands CCL19 and CCL21 control a whole range of events in adaptive immunity. Apart from other 
functions, CCR7 and its ligands appear to play a complex role in stimulating $\mathrm{T}$ cell activation and acting as co-stimulatory factors in priming $\mathrm{T}$ cells promoting $\mathrm{T}$ helper 1 and $\mathrm{T}$ helper 17 responses (Kuwabara et al. 2009). In the present study, a higher expression of the CCR7 gene was observed in the long-term group. An influx of macrophages towards peritoneal cavity in long-term PD patient and in an experimental model of peritoneal fibrosis has been reported (Hu et al. 2012). Our data demonstrated that the proportion of monocytes increased with the time on PD. The higher expression of the $C C R 7$ gene might reflect M1 phenotype macrophages activation as the consequence of permanent stimulation by hyperosmolar glucose and AGEs in dialysis fluid during long-term PD treatment. Subsequently activation of $\mathrm{T}$ cells is induced promoting profibrotic processes.

The membrane alterations in long-term PD are accompanied with modifications of peritoneal capillaries and neoangiogenesis (Mateijsen et al. 1999). Vascular endothelial growth factor (VEGF) is supposed to be involved. Kariya et al. (2018) found increased levels of VEGF-A mRNA levels in the peritoneum of patients with ultrafiltration failure, which were related to the number of vessels and peritoneal thickness. In the present study a higher expression of the CEACAM1 gene was found in the long-term group. CEACAM1 is a major effector of VEGF in the early microvessel formation, augments the effect of VEGF, and on the other hand, VEGF increases CEACAM1 expression both on the mRNA and the protein level (Ergün et al. 2000). A less known function of CEACAM is its involvement in the biosynthesis of collagen. The presence of CEACAM dimers has been shown to increase the binding of the $\alpha 5 \beta 1$ integrin receptor to its ligand fibronectin to induce a conformational change in collagen to accelerate fibrillogenesis (Li et al. 2003).

The cross-sectional design is a weak point of the present study. However, a comparison of the whole transcriptome of cells in PD effluent in individual patients in relationship with PD duration and with functional changes is unique to our knowledge. In the present analysis we have demonstrated that already before the development of alterations in peritoneal function, the mechanisms of adaptive immunity promoting $\mathrm{T}$ helper cells response are activated in longterm PD. As adaptive immunity is antigen specific, the number of infectious complications is likely to play the role. The switch in immune response from Th1 apparent in short-term, to Th2 cells in long-term might trigger the fibrosis promoting processes.

\section{Conflict of Interest}

There is no conflict of interest.

\section{Acknowledgements}

The authors thank the nurses and patients for the cooperation and help. This work was supported by Ministry of Health of the Czech Republic, grant Nr. 15-26638A. All rights reserved. The authors of this manuscript have no conflicts of interest to disclose.

\section{References}

ALLAM A, NIIRO H, CLARK EA, MARSHALL AJ: The adaptor protein Bam32 regulates Rac1 activation and actin remodeling through a phosphorylation-dependent mechanism. J Biol Chem 279: 39775-39782, 2004.

AUFRICHT C, BEELEN R, EBERL M, FISCHBACH M, FRASER D, JORRES A, KRATOCHWILL K, LOPEZCABRERA M, RUTHERFORD P, SCHMITT CP, TOPLEY N, WITOWSKI J: Biomarker research to improve clinical outcomes of peritoneal dialysis: consensus of the European Training and Research in Peritoneal Dialysis (EuTRiPD) network. Kidney Int 92: 824-835, 2017.

BETJES MG, HABIB MS, STRUIJK DG, LOPES BARRETO D, KORTE MR, ABRAHAMS AC, NAGTZAAM NM, CLAHSEN-VAN GRONINGEN MC, DIK WA, LITJENS NH: Encapsulating peritoneal sclerosis is associated with T-cell activation. Nephrol Dial Transplant 30: 1568-1576, 2015.

CHATTERJEE M, RAUEN T, KIS-TOTH K, KYTTARIS VC, HEDRICH CM, TERHORST C, TSOKOS GC: Increased expression of SLAM receptors SLAMF3 and SLAMF6 in systemic lupus erythematosus T lymphocytes promotes Th17 differentiation. J Immunol 188: 1206-1212, 2012.

CNOSSEN TT, SMIT W, KONINGS CJ, KOOMAN JP, LEUNISSEN KM, KREDIET RT: Quantification of free water transport during the peritoneal equilibration test. Perit Dial Int 29: 523-527, 2009.

DAVIES SJ: Peritoneal solute transport and inflammation. Am J Kidney Dis 64: 978-986, 2014. 
ERGÜN S, KILIK N, ZIEGELER G, HANSEN A, NOLLAU P, GÖTZE J, WURMBACH JH, HORST A, WEIL J, FERNANDO M, WAGENER C: CEA-related cell adhesion molecule 1: a potent angiogenic factor and a major effector of vascular endothelial growth factor. Mol Cell 5: 311-320, 2000.

FIELDING CA, JONES GW, MCLOUGHLIN RM, MCLEOD L, HAMMOND VJ, UCEDA J, WILLIAMS AS, LAMBIE M, FOSTER TL, LIAO CT, RICE CM, GREENHILL CJ, COLMONT CS, HAMS E, COLES B, KIFT-MORGAN A, NEWTON Z, CRAIG KJ, WILLIAMS JD, WILLIAMS GT, DAVIES SJ, HUMPHREYS IR, O'DONNELL VB, TAYLOR PR, JENKINS BJ, TOPLEY N, JONES SA: Interleukin-6 signaling drives fibrosis in unresolved inflammation. Immunity 40: 40-50, 2014.

GRAHAM DB, BELL MP, MCCAUSLAND MM, HUNTOON CJ, VAN DEURSEN J, FAUBION WA, CROTTY S, MCKEAN DJ: Ly9 (CD229)-deficient mice exhibit $\mathrm{T}$ cell defects yet do not share several phenotypic characteristics associated with SLAM- and SAP-deficient mice. J Immunol 176: 291-300, 2006.

HARDING HP, CALFON M, URANO F, NOVOA I, RON D: Transcriptional and translational control in the Mammalian unfolded protein response. Annu Rev Cell Dev Biol 18: 575-599, 2002.

HASEGAWA M, FUJIMOTO M, TAKEHARA K, SATO S: Pathogenesis of systemic sclerosis: altered B cell function is the key linking systemic autoimmunity and tissue fibrosis. J Dermatol Sci 39: 1-7, 2005.

HU W, JIANG Z, ZHANG Y, LIU Q, FAN J, LUO N, DONG X, YU X: Characterization of infiltrating macrophages in high glucose-induced peritoneal fibrosis in rats. Mol Med Rep 6: 93-99, 2012.

KARIYA T, NISHIMURA H, MIZUNO M, SUZUKI Y, MATSUKAWA Y, SAKATA F, MARUYAMA S, TAKEI Y, ITO Y: TGF- $\beta 1$-VEGF-A pathway induces neoangiogenesis with peritoneal fibrosis in patients undergoing peritoneal dialysis. Am J Physiol Renal Physiol 314: F167-F180, 2018.

KLINGER M, KIM JK, CHMURA SA, BARCZAK A, ERLE DJ, KILEEN N: Thymic OX40 expression discriminates cells undergoing strong responses to selection ligands. J Immunol 182: 4581-4589, 2009.

KUWABARA T, ISHIKAWA F, YASUDA T, ARITOMI K, NAKANO H, TANAKA Y, OKADA Y, LIPP M, KAKIUCHI T: CCR7 ligands are required for development of experimental autoimmune encephalomyelitis through generating IL-23-dependent Th17 cells. J Immunol 183: 2513-2521, 2009.

LI X, RAYFORD H, UHAL BD: Essential roles for angiotensin receptor AT1a in bleomycin-induced apoptosis and lung fibrosis in mice. Am J Pathol 163: 2523-2530, 2003.

LIAO W, LIN JX, LEONARD WJ: IL-2 family cytokines: new insights into the complex roles of IL-2 as a broad regulator of T helper cell differentiation. Curr Opin Immunol 23: 598-604, 2011.

MATEIJSEN MA, VAN DER WAL AC, HENDRIKS PM, ZWEERS MM, MULDER J, STRUIJK DG, KREDIET RT: Vascular and interstitial changes in the peritoneum of CAPD patients with peritoneal sclerosis. Perit Dial Int 19: 517-525, 1999.

MOSSER DM, EDWARDS JP: Exploring the full spectrum of macrophage activation. Nat Rev Immunol 8: 958-969, 2008.

OHASHI K, TAKAHASHI HK, MORI S, LIU K, WAKE H, SADAMORI H, MATSUDA H, YAGI T, YOSHINO T, NISHIBORI M, TANAKA N: Advanced glycation end products enhance monocyte activation during human mixed lymphocyte reaction. Clin Immunol 134: 345-353, 2010.

OHSHIMA Y, YANG LP, UCHIYAMA T, TANAKA Y, BAUM P, SERGERIE M, HERMANN P, DELESPESSE G: OX40 costimulation enhances interleukin-4 (IL-4) expression at priming and promotes the differentiation of naive human CD4(+) T cells into high IL-4-producing effectors. Blood 92: 3338-3345, 1998.

PESCE J, KAVIRATNE M, RAMALINGAM TR, THOMPSON RW, URBAN JF, CHEEVER AW, YOUNG DA, COLLINS M, GRUSBY MJ, WYNN TA: The IL-21 receptor augments Th2 effector function and alternative macrophage activation. J Clin Invest 116: 2044-2055, 2006.

RODRIGUES-DIEZ R, AROEIRA LS, OREJUDO M, BAJO MA, HEFFERNAN JJ, RODRIGUES-DIEZ RR, RAYEGO-MATEOS S, ORTIZ A, GONZALES-MATEO G, LOPEZ-CABRERA M, SELGAS R, EGIDO J, RUIZ-ORTEGA M: IL-17A is a novel player in dialysis-induced peritoneal damage. Kidney Int 86: 303-315, 2014.

SMIT W, VAN DIJK P, LANGEDIJK MJ, SCHOUTEN N, VAN DEN BERG N, STRUIJK DG, KREDIET RT: Peritoneal function and assessment of reference values using a $3.86 \%$ glucose solution. Perit Dial Int 23: 440-449, 2003. 
TRIPLETT TA, CURTI BD, BONAFEDE PR, MILLER WL, WALKER EB, WEINBERG AD: Defining a functionally distinct subset of human memory CD4+ $\mathrm{T}$ cells that are CD25POS and FOXP3NEG. Eur J Immunol 42: 1893-1905, 2012.

WYNN TA: Cellular and molecular mechanisms of fibrosis. J Pathol 214: 199-210, 2008.

YASUDA S, ZHOU Y, WANG Y, YAMAMURA M, WANG JY: A model integrating tonic and antigen-triggered BCR signals to predict the survival of primary B cells. Sci Rep 7: 14888, 2017. 